University of Nebraska - Lincoln

DigitalCommons@University of Nebraska - Lincoln

Faculty Papers and Publications in Animal

Science

Animal Science Department

2-6-2001

\title{
Identification of quantitative trait loci affecting reproduction in pigs
}

\author{
J. P. Cassady \\ University of Nebraska-Lincoln \\ R. K. Johnson \\ University of Nebraska-Lincoln, rjohnson5@unl.edu \\ Daniel Pomp \\ University of Nebraska-Lincoln, dpomp1@unl.edu
}

G. A. Rohrer

USDA-ARS, gary.rohrer@ars.usda.gov

\section{Dale Van Vleck}

USDA-ARS, U.S. Meat Animal Research Center, Lincoln, NE, dvan-vleck1@unl.edu

See next page for additional authors

Follow this and additional works at: https://digitalcommons.unl.edu/animalscifacpub

Part of the Animal Sciences Commons

\footnotetext{
Cassady, J. P.; Johnson, R. K.; Pomp, Daniel; Rohrer, G. A.; Van Vleck, L. Dale; Spiegel, E. K.; and Gilson, K. M., "Identification of quantitative trait loci affecting reproduction in pigs" (2001). Faculty Papers and Publications in Animal Science. 100.

https://digitalcommons.unl.edu/animalscifacpub/100

This Article is brought to you for free and open access by the Animal Science Department at DigitalCommons@University of Nebraska - Lincoln. It has been accepted for inclusion in Faculty Papers and Publications in Animal Science by an authorized administrator of DigitalCommons@University of Nebraska - Lincoln.
} 


\section{Authors}

J. P. Cassady, R. K. Johnson, Daniel Pomp, G. A. Rohrer, L. Dale Van Vleck, E. K. Spiegel, and K. M. Gilson 


\title{
Identification of quantitative trait loci affecting reproduction in pigs ${ }^{1,2,3}$
}

\author{
J. P. Cassady*,4,5, R. K. Johnson*,6, D. Pomp*, G. A. Rohrer $\dagger$, L. D. Van Vleck ${ }^{*}$, \\ E. K. Spiegel*, and K. M. Gilson* \\ *Animal Science Department, University of Nebraska, Lincoln 68583-0908; †USDA-ARS, U.S. Meat Animal \\ Research Center, Clay Center, NE 68933-0166; and $¥$ USDA-ARS, U.S. Meat Animal Research Center, \\ Lincoln, NE 68583-0908
}

\begin{abstract}
The objective of this research was to identify chromosomal regions harboring QTL affecting reproduction in pigs. A three-generation resource population was developed by crossing low-indexing pigs from a randomly selected control line $(\mathrm{C})$ with high-indexing pigs of a line selected for increased index of ovulation rate and embryonic survival (I). Differences between Lines $\mathrm{I}$ and $\mathrm{C}$ at Generation 10 were 6.7 ova and 3.3 fetuses at $50 \mathrm{~d}$ of gestation and 3.1 fully formed and 1.6 live pigs at birth. Phenotypic data were collected on $\mathrm{F}_{2}$ females, born in three replicates, for ovulation rate $(\mathrm{n}=423)$, age at puberty $(\mathrm{n}=295)$, litter size $(\mathrm{n}=$ $370)$, and number of nipples $(\mathrm{n}=428)$. Litter-size data included number of fully formed, live, stillborn, and mummified pigs. Grandparent, $\mathrm{F}_{1}$, and $\mathrm{F}_{2}$ animals were genotyped for 151 microsatellite markers distributed across all 18 autosomes and the $\mathrm{X}$ chromosome. Genotypic data were available on $423 \mathrm{~F}_{2}$ females. Average spacing between markers was 19.3 Kosambi centi-
\end{abstract}

morgans. Calculations of logarithms of odds (LOD) scores were by least squares, and fixed effects for siredam combination and replicate were included in the models. Genome-wide significance level thresholds of $5 \%$ and $10 \%$ were calculated using a permutation approach. There was evidence $(P<0.05)$ for QTL affecting ovulation rate on SSC9, age at puberty on SSC7 and SSC8, number of nipples on SSC8 and SSC11, number of stillborn pigs on SSC5 and SSC13, and number of fully formed pigs on SSC11. There was evidence $(P<$ 0.10 ) for additional QTL affecting age at puberty on SSC7, SSC8, and SSC12, number born live on SSC11, and number of nipples on SSC1, SSC6, and SSC7. Litter size is lowly heritable and sex-limited. Therefore, accuracy of selection for litter size may be enhanced by marker-assisted selection. Ovulation rate and age at puberty are laborious to measure, and thus markerassisted selection may provide a practical and efficient method of selection.

Key Words: Pigs, Quantitative Trait Loci, Reproduction

(C2001 American Society of Animal Science. All rights reserved.

J. Anim. Sci. 2001. 79:623-633

\section{Introduction}

Response to direct selection for litter size has been slow because heritability is low and litter size is sexlimited (Ollivier, 1982; Lamberson et al., 1991). Johnson et al. (1984) and Bennett and Leymaster (1989)

\footnotetext{
${ }^{1}$ Published as paper no. 12943, Journal Ser. Nebraska Agric. Res. Div.

${ }^{2}$ Mention of trade names is necessary to report factually on available data; however, the USDA neither guarantees nor warrants the standard of the product, and the use of the name by USDA implies no approval of the product to the exclusion of others that may also be available.

${ }^{3}$ This research was partially funded by USDA National Research Initiative and Competitive Grant 96-35205-3437 program and contributed to objectives of the NC 220 Regional Research and NRSP8 National Research Programs.

Received March 24, 2000.

Accepted November 13, 2000.
}

suggested that greater response can be expected from selection for an index of ovulation rate and embryonic survival or uterine capacity than from direct selection. Johnson et al. (1999) reported increases in number of fully formed and live pigs at birth in response to 14 generations of selection for ovulation rate, embryonic survival, and litter size. Marker-assisted selection (MAS) may be a method of selecting for components of litter size in both sexes at a very young age and improving accuracy of selection. Simulation studies have demonstrated potential benefits of MAS (Zhang and Smith, 1992, 1993; Edwards and Page, 1994). Efficiency of

\footnotetext{
${ }^{4}$ We are grateful to the USDA-supported U.S. Pig Genome Coordination Project for partial support of purchase of labeled PCR primers used in this research.

${ }^{5}$ Current address: USDA-ARS, Roman L. Hruska U.S. Meat Animal Research Center, P.O. Box 166, Clay Center, NE 68933-0166.

${ }^{6}$ Correspondence and reprint requests: A218 Animal Sciences (phone: 402/472-6404; fax: 402/472-6362; E-mail: rkjohnso@unl.edu).
} 
Table 1. Generation 10 phenotypic means for the control and index lines

\begin{tabular}{lccccccc}
\hline \hline Line & Ovulation rate $^{\mathrm{a}}$ & Fetuses $^{\mathrm{b}}$ & Fully formed $^{\mathrm{c}}$ & Born alive $^{\mathrm{d}}$ & Embryonic survival, \% $^{\mathrm{e}}$ & Age of puberty $^{\mathrm{df}}$ & No. of nipples $^{\mathrm{g}}$ \\
\hline Control & 13.80 & 10.30 & 9.51 & 9.15 & 76.2 & 182 & 14.8 \\
Index & 20.44 & 13.64 & 12.58 & 10.74 & 71.6 & 192 & 14.8 \\
\hline
\end{tabular}

${ }^{a}$ Number of corpora lutea at $50 \mathrm{~d}$ of gestation.

${ }^{\mathrm{b}}$ Number of fetuses at $50 \mathrm{~d}$ of gestation.

${ }^{\mathrm{c} N u m b e r}$ of fully formed pigs at birth.

${ }^{\mathrm{d}}$ Number of pigs born alive.

eEmbryonic survival was calculated as the percentage of corpora lutea represented by number of fetuses at $50 \mathrm{~d}$ gestation.

${ }^{\mathrm{f}}$ Age of first observed estrus in $d$.

gNumber of nipples measured on pigs at birth.

MAS relative to phenotypic selection is greatest for lowly heritable and sex-limited traits (Lande and Thompson, 1990). Simulation of response to MAS has been shown to be greater than response to selection on either phenotypes or markers alone (Zhang and Smith, 1992).

To implement MAS, QTL must be identified and their effects estimated. Several QTL affecting growth and carcass composition have been identified in pigs. Relatively few QTL explaining a significant proportion of the genetic variance for litter size and its component traits have been identified. Evidence of QTL affecting number of corpora lutea on SSC3 (Rohrer et al., 1999), SSC8 (Rathje et al., 1997; Rohrer et al., 1999; Wilkie et al., 1999), and SSC10 (Rohrer et al., 1999) has been reported. Wilkie et al. (1999) also reported evidence of a QTL associated with number of stillborn pigs on SSC4. The objective of this research was to identify chromosomal regions harboring QTL that explain a portion of genetic variance associated with reproduction in pigs.

\section{Materials and Methods}

\section{Population}

An $\mathrm{F}_{2}$ resource population was created at the University of Nebraska (Rathje et al., 1997). Grandparent animals were selected from a line that had been selected 10 generations for an index (I) of ovulation rate and embryonic survival or its randomly selected control (C). Means for Generation 10 are given in Table 1. Twelve high-indexing females and five males out of high-indexing dams were selected from Line I. Fourteen lowindexing females and four males out of low-indexing dams were selected from Line C. Line I males were randomly mated to Line $\mathrm{C}$ females, and Line $\mathrm{C}$ males were randomly mated to Line $\mathrm{I}$ females to create $\mathrm{F}_{1}$ pigs. Fifty $\mathrm{F}_{1}$ females, with at least one randomly selected per full-sib family, were mated with $10 \mathrm{~F}_{1}$ males, with at least one randomly selected from each paternal halfsib family, to produce $\mathrm{F}_{2}$ progeny. The $\mathrm{F}_{2}$ progeny were born in three replicates. Replicate 1 was produced by randomly mating $\mathrm{F}_{1}$ animals while avoiding full-sib and half-sib matings. Replicate 2 progeny were produced by a second set of random matings. To increase the number of full-sibs, the matings made in Replicate 2 were repeated for Replicate 3 . In total, there were $428 \mathrm{~F}_{2}$ females from 79 full-sib families.

\section{Measurement of Traits}

Number of nipples was recorded at birth. At 8 mo of age, $\mathrm{F}_{2}$ gilts were naturally mated to unrelated crossbred boars. At parturition, numbers of fully formed, stillborn, live, and mummified pigs were recorded. Pigs were weaned at approximately $12 \mathrm{~d}$ of age.

A management constraint imposed to prevent transmission of a particular disease to Replicate 1 animals prevented measurement of age at puberty. After weaning their litters, sows of Replicate 1 were monitored daily for estrus. Between 7 and $14 \mathrm{~d}$ after expression of estrus, sows were slaughtered and reproductive tracts were recovered. Ovaries were dissected and number of corpora lutea was recorded as a measure of ovulation rate. Age at puberty was recorded in Replicate 2 and 3 gilts by exposing them daily to mature boars and observing for signs of estrus. Seven to $14 \mathrm{~d}$ after second expression of estrus, laparotomy was performed and number of corpora lutea was recorded.

\section{Tissue Collection}

White blood cells, liver tissues, and tail tissues were all used as sources of DNA. After collection, tissues were immediately placed on ice for transport to the laboratory. Samples were stored at $-20^{\circ} \mathrm{C}$ or colder. Whole blood samples $(100 \mathrm{~mL})$ were collected via jugular venipuncture from grandparents, $F_{1}$ dams, and $F_{2}$ Replicate 2 pigs. Blood samples from $\mathrm{F}_{1}$ dams and $\mathrm{F}_{2}$ Replicate 2 pigs were centrifuged, and white blood cells were removed and stored for DNA extraction. Tail tissues were collected from all $\mathrm{F}_{1}$ and $\mathrm{F}_{2}$ pigs at 1 to $3 \mathrm{~d}$ of age. Liver samples were collected from grandparents, $\mathrm{F}_{1}$ boars, and $\mathrm{F}_{2}$ Replicate 1 pigs at slaughter.

\section{Laboratory Procedures}

Microsatellite markers were preselected from the USDA swine linkage map (Rohrer et al., 1996) for testing based on their location and informativeness in two sires (white composite) in the USDA-ARS, U.S. Meat Animal Research Center (MARC) (Keele et al., 1994) 
database. The two sires used for prescreening markers had a genetic background similar to that of the pigs in this study. Markers heterozygous in one or both of these boars were screened through a sample of grandparents to determine their informativeness. Markers known to have a null allele were not used. A total of 151 microsatellite markers were considered to be informative, genotyped in the entire population, and used in the final analysis.

Genomic DNA was obtained from tissues using a proteinase $\mathrm{K}$ digestion followed by phenol/chloroform extraction and precipitation with isopropanol. The DNA concentration was determined using spectrophotometry. Samples were diluted to a standardized concentration of $50 \mathrm{ng} / \mu \mathrm{L}$.

Primer pair sequences for markers identified for testing in the Nebraska resource population were obtained from the USDA database (USDA, 1996). Primers were synthesized (Li-Cor, Lincoln, NE) attaching one of two fluorescent infrared dyes (IRD700 or IRD800) to the 5' end of each forward primer.

Genotyping was done in 96-well plates using PCR and denaturing gel electrophoresis. A Li-Cor Model $4200 \mathrm{IR}^{2}$ System was used. A $10-\mu \mathrm{L}$ PCR reaction was used. Ingredients included $1 \times$ supplied Taq buffer ( $\mathrm{MgCl}_{2}$-free), $0.2 \mathrm{mM}$ each dNTP, 0.5 unit Taq Gold polymerase (Perkin Elmer, Foster City, CA), $2.5 \mathrm{mM}$ $\mathrm{MgCl}_{2}$, and $50 \mathrm{ng}$ of genomic DNA. Primers were tested to optimize amount of forward labeled primer, which was added at $0.1,0.2$, or 0.3 pmol. Reverse primer was always added at 1 pmol. Reactions were done using a "touchdown" PCR protocol in MJ Tetrad thermal cyclers (MJ Research, Waltham, MA). For eight cycles annealing temperatures were decreased $2^{\circ} \mathrm{C}$ per cycle ranging

Table 2. Microsatellite markers used in the Nebraska resource population

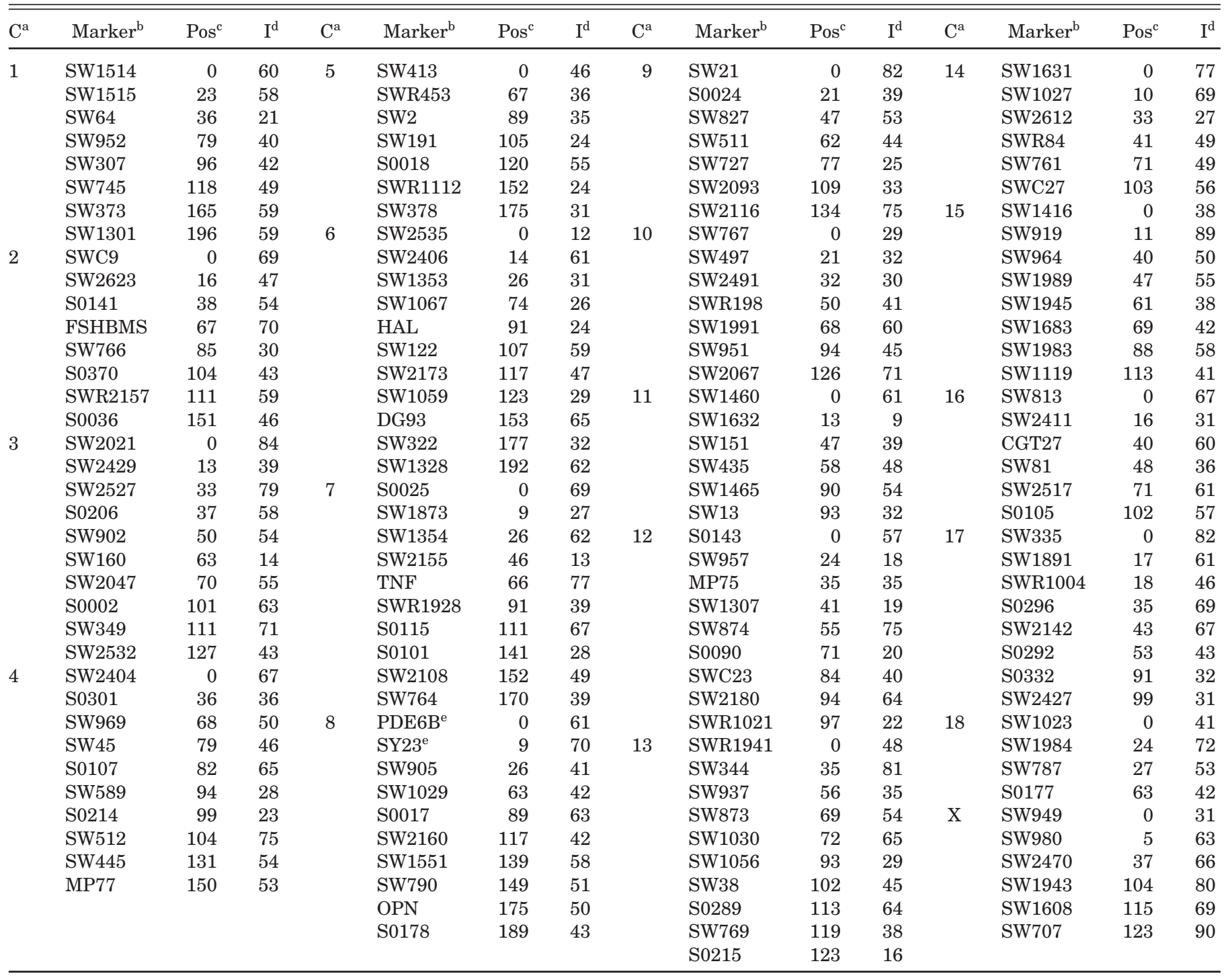

${ }^{\mathrm{a}}$ Chromosome.

${ }^{\mathrm{b}}$ Primer sequences may be found at http://www.marc.usda.gov/genome/swine/.

${ }^{c}$ Positions are reported in Kosambi centimorgans.

dPercentage of $\mathrm{F}_{1}$ meioses for which allelic line of origin could be determined.

eUnpublished microsatellite markers (G. Rohrer and E. Campbell, unpublished data). 
Table 3. Phenotypic mean, standard deviation, and range for grandparents, $F_{1}$, and $F_{2}$ gilts

\begin{tabular}{|c|c|c|c|c|c|c|c|c|}
\hline Trait & $\mathrm{n}$ & Mean & SD & Range & $\mathrm{n}$ & Mean & $\mathrm{SD}$ & Range \\
\hline & \multicolumn{4}{|c|}{ Index line, grandparent females } & \multicolumn{4}{|c|}{ Control line, dams of grandparent males } \\
\hline Number of nipples & 12 & 14.1 & 1.4 & $12-17$ & 4 & 14.5 & - & $13-16$ \\
\hline Age at puberty & 12 & 182.5 & 22.8 & $145-227$ & 4 & 162.5 & - & $130-204$ \\
\hline Ovulation rate & 12 & 32.1 & 16.8 & $14-65$ & 4 & 11.3 & - & 9-14 \\
\hline Pigs born alive & 12 & 9.5 & 3.2 & $6-14$ & 4 & 7.0 & - & $6-8$ \\
\hline Stillborn pigs & 12 & 1.8 & 1.1 & $0-3$ & 4 & 0.5 & - & $0-2$ \\
\hline Mummified pigs & 12 & 1.58 & 1.2 & $0-3$ & 4 & 0.5 & - & $0-1$ \\
\hline \multirow[t]{2}{*}{ Fully formed pigs } & 12 & 11.3 & 3.3 & $6-16$ & 4 & 7.5 & - & $6-8$ \\
\hline & \multicolumn{4}{|c|}{ Control line, grandparent females } & \multicolumn{4}{|c|}{$\mathrm{F}_{1}$ females } \\
\hline Number of nipples & 14 & 14.4 & .8 & $13-16$ & 43 & 14.5 & 1.1 & $12-17$ \\
\hline Age at puberty & 14 & 182.4 & 39.6 & $145-277$ & 43 & 187.2 & 28.2 & $141-231$ \\
\hline Ovulation rate & 14 & 13.5 & 2.2 & $11-18$ & 43 & 15.9 & 2.5 & $13-21$ \\
\hline Pigs born alive & 14 & 8.3 & 2.1 & $5-11$ & 39 & 10.1 & 2.8 & $4-15$ \\
\hline Stillborn pigs & 14 & 0.4 & 0.6 & $0-2$ & 39 & 0.7 & 1.0 & $0-4$ \\
\hline Mummified pigs & 14 & 0.1 & 0.4 & $0-1$ & 39 & 0.5 & 1.4 & $0-8$ \\
\hline \multirow[t]{2}{*}{ Fully formed pigs } & 14 & 8.6 & 2.3 & $5-11$ & 39 & 10.9 & 3.0 & $4-16$ \\
\hline & \multicolumn{4}{|c|}{ Index line, dams of grandparent males } & \multicolumn{4}{|c|}{$\mathrm{F}_{2}$ females } \\
\hline Number of nipples & 5 & 15.4 & - & $14-18$ & 428 & 14.3 & 1.3 & $11-19$ \\
\hline Age at puberty & 5 & 169.0 & - & $150-220$ & 295 & 181.3 & 23.6 & $134-231$ \\
\hline Ovulation rate & 5 & 53.0 & - & $38-79$ & 423 & 15.8 & 3.3 & 8-44 \\
\hline Pigs born alive & 5 & 9.0 & - & $5-11$ & 370 & 10.5 & 2.7 & $0-17$ \\
\hline Stillborn pigs & 5 & 0.6 & - & $0-2$ & 370 & 0.9 & 1.4 & $0-11$ \\
\hline Mummified pigs & 5 & 1.8 & - & $0-4$ & 370 & 0.5 & 0.9 & $0-8$ \\
\hline Fully formed pigs & 5 & 9.6 & - & $5-13$ & 370 & 11.4 & 2.7 & $1-19$ \\
\hline
\end{tabular}

from $68^{\circ} \mathrm{C}$ to $54^{\circ} \mathrm{C}$. This was followed by 30 cycles with an annealing temperature of $54^{\circ} \mathrm{C}$. The PCR product was diluted 2:1 with stop buffer and denatured for 2.5 $\mathrm{m}$ at $95^{\circ} \mathrm{C}$. The product was then placed on ice and loaded into a 7\% denaturing polyacrylamide gel.

Each genotype was manually scored by two independent technicians using RFLPscan Plus version 3.0 (Scanalytics, Fairfax, VA). Genotypes were then compared and those not in agreement were re-evaluated. If a clear agreement could not be reached, genotypes were regenerated or entered as missing data. Occurrence of missing genotypes was $1.4 \%$. Marker data were analyzed to identify deviations from Mendelian segregation. This analysis revealed that tissue samples collected for the grandsires were incorrectly identified. Therefore, all grandsires were genotyped retrospectively using information from granddams and $\mathrm{F}_{1}$ progeny. Grandsires that passed the same allele to each of their progeny were scored as having one allele known and one allele missing. Thus, grandsires were never scored as homozygous. Power was lost only in cases in which an $\mathrm{F}_{1}$ progeny and its dam were like-heterozygotes and the sire had one known and one unknown allele. This situation occurred only $7 \%$ of the time. Loss of power was actually less than $7 \%$ because some grandsires and granddams were probably like-heterozygotes, in which case the marker would not be informative. In addition, the program of Haley et al. (1994), used to calculate coefficients of additive and dominance effects, considers the entire linkage group and continues along it until a marker with known line of origin is found. Thus, some information lost at a single locus would have been recovered using adjacent markers.

Genotypes for one $\mathrm{F}_{1}$ sire did not match those of any of the grandparents. The cause was incorrect identification during cross-fostering to standardize litter size. This boar came from the same population, but its exact parentage was not known. This boar sired $53 \mathrm{~F}_{2}$ females. A fictitious sire and dam were created for the boar and their genotypes were entered as missing data. Therefore, this sire was completely uninformative, although line of origin information can still be partially attained for these pigs through their dams.

\section{Statistical Analysis}

Genotypic data were first analyzed using CRIMAP version 2.4 (Green et al., 1990) to estimate distance between markers. The CHROMPIC option of CRIMAP was used to identify potential genotyping errors. Cases in which three crossovers were indicated within a linkage group were rechecked for accuracy.

The method and program described by Haley et al. (1994) were used to calculate coefficients of additive and dominance effects. A least squares approach was then used to regress phenotypic data using the coefficients of additive and dominance effects as covariates. Two models were compared. Both models included fixed 
effects of replicate and sire-dam combination. Sire-dam combination was included as a fixed effect to adjust for polygenic effects.

One model included covariate coefficients of additive and dominance effects, and the other excluded the coefficients of additive and dominance effects. The reduced model can be written as $\mathbf{y}=\mathbf{X b}+\mathbf{e}$, where $\mathbf{y}, \mathbf{b}$, and $\mathbf{e}$ are vectors of phenotypic, fixed, and residual effects, respectively, and $\mathbf{X}$ is a known design matrix. The full model was $\mathbf{y}=\mathbf{a c}_{1}+\mathbf{d} \mathbf{c}_{2}+\mathbf{X b}+\mathbf{e}$, where $\mathbf{y}, \mathbf{b}, \mathbf{e}$, and $\mathbf{X}$ are as previously described and $\mathbf{c}_{1}$ and $\mathbf{c}_{2}$ are vectors of coefficients of the additive (a) and dominance (d) effects, respectively. The additive coefficient was computed as the difference between the probability that a homozygous individual inherited both alleles from Line $\mathrm{C}$ and the probability that it inherited both alleles from Line I. The dominance coefficient is the probability that an individual is heterozygous. The program of Haley et al. (1994) produces the regression of phenotype on the additive coefficient as the deviation of individuals that are homozygous for the allele inherited from line $\mathrm{C}$ from the mean of the two homozygous genotypes. The regression of phenotype on the dominance coefficient is the deviation of heterozygous individuals from the mean of the two homozygous genotypes.

Genome-wide critical $\alpha=0.05$ and $\alpha=0.10$ levels were estimated using a permutation analysis with 1,000 random data shuffles as described by Churchill and Doerge (1994). While shuffling data, associations between fixed effects and phenotypes were retained.

A preliminary least squares regression analysis was done to determine whether a single permutation threshold could be used for all traits or whether permutation thresholds differed significantly among traits. At the time of the preliminary analysis only SSC15 data were available. Phenotypic data from each trait and genotypic data from SSC15 were shuffled 7,300 times and analyzed. Data from all seven traits were combined $(\mathrm{n}=51,100)$ and LOD scores were ranked from greatest to least. The LOD exceeding the 95th percentile was LOD $=2.55$. Next, data from each trait $(n=7,300)$ were ranked from greatest to least, and the number of observations exceeding LOD $=2.55$ was determined. Chi-square was used to test differences between expected and observed number of observations exceeding $\mathrm{LOD}=2.55$. It was determined that thresholds for each trait should be estimated independently. A total of 19,000 LOD scores for each trait were calculated, with 1,000 permutations for each chromosome. The 19,000 LOD scores were then ranked. Thresholds for a critical value of $\alpha=0.05$ and $\alpha=0.10$ were the LOD scores that exceeded the 95th and 90th percentiles, respectively. These are values that a LOD score would exceed by chance only $5 \%$ or $10 \%$ of the time, respectively, when considering the entire genome.

Table 4. Estimates of additive (a) and dominance (d) effects and standard errors for putative QTL affecting reproduction in the pig

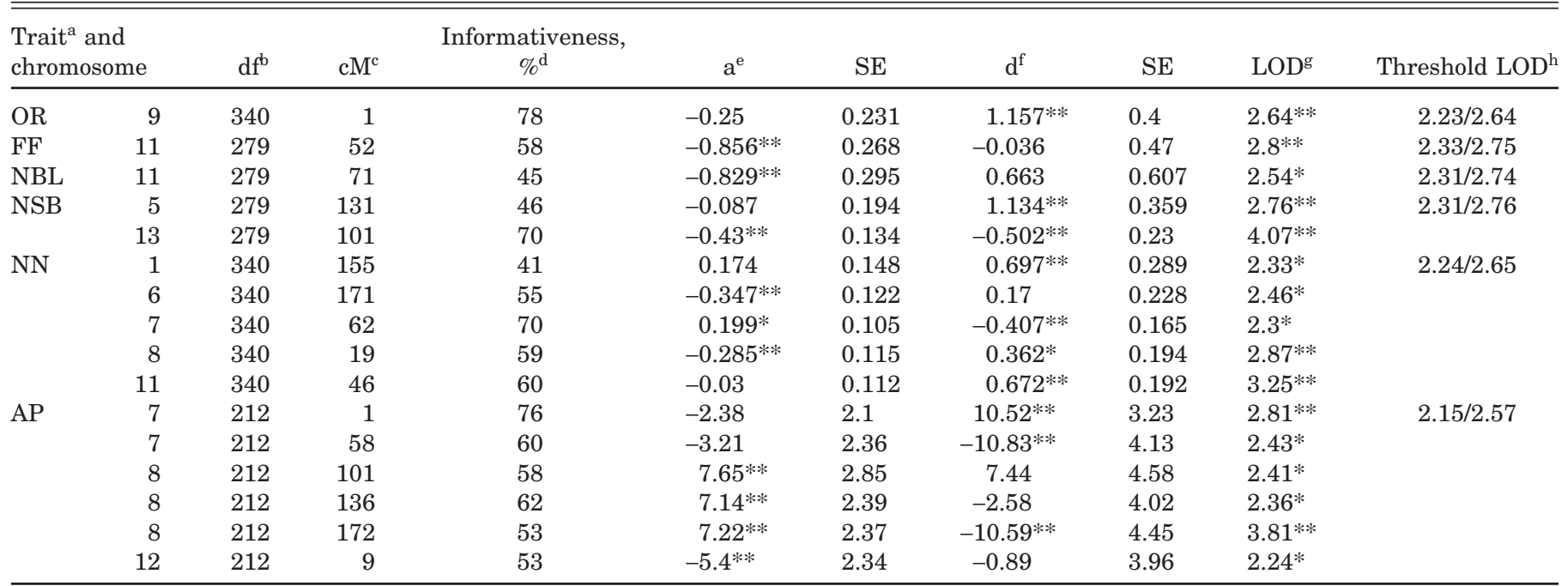

\footnotetext{
${ }^{\mathrm{a}} \mathrm{OR}=$ ovulation rate, $\mathrm{AP}=$ age at puberty, $\mathrm{NN}=$ number of nipples, and FF, NBL, and NSB = number of fully formed, stillborn, and live pigs at birth, respectively.

${ }^{\mathrm{b}}$ Degrees of freedom equal $\mathrm{N}$ - the rank of the incidence matrix $\mathbf{X}$ in $\mathbf{y}=\mathbf{X b}+\mathbf{e}$.

${ }^{\mathrm{c}}$ Relative position in Kosambi centimorgans, based on the map reported in Table 2.

${ }^{\mathrm{d}}$ Informativeness is the percentage of $\mathrm{F}_{1}$ meioses that could be traced back to the line of origin at the putative QTL position.

${ }^{\mathrm{e}}$ Additive effects are estimates of the value of pigs homozygous for the allele inherited from the control line deviated from the mean of the two homozygous genotypes, expressed as pigs for litter traits, corpora lutea for ovulation rate, nipples for nipple number, and days for age at puberty.

${ }^{\mathrm{f}}$ Dominance effects are estimates of the value of the heterozygous genotype compared to the mean of the two homozygous genotypes.

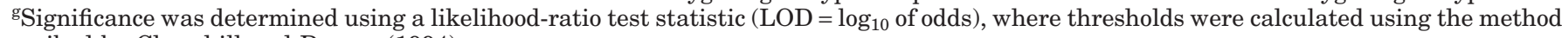
described by Churchill and Doerge (1994).

$\mathrm{h}_{\alpha}=0.10 / \alpha=0.05$ thresholds calculated using a permutation approach.

*Genome-wide significance threshold of $P<0.10$.

$* *$ Genome-wide significance threshold of $P<0.05$.
} 


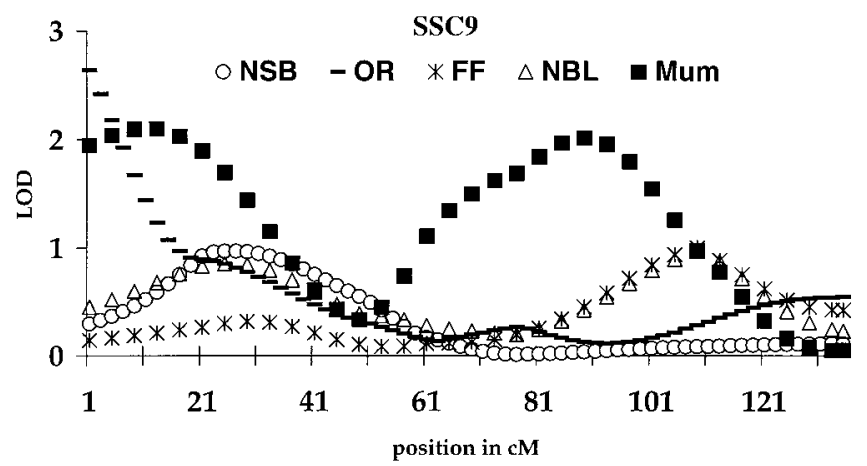

c

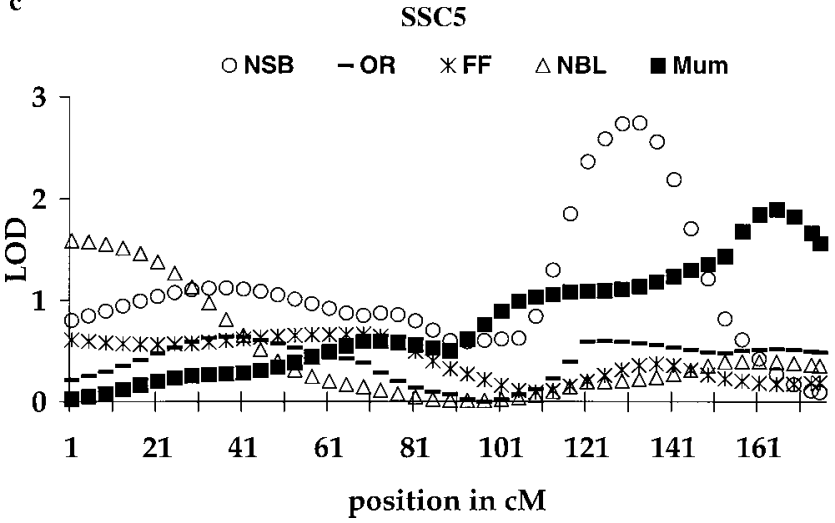

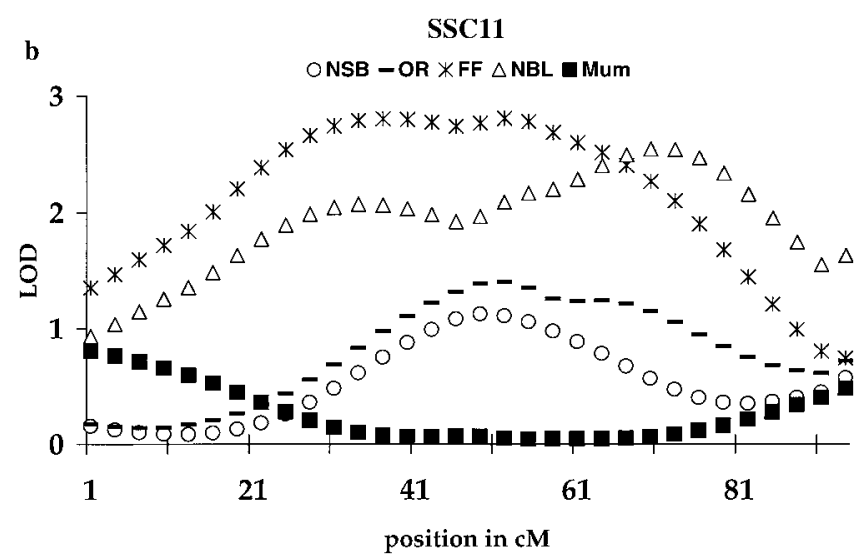

d

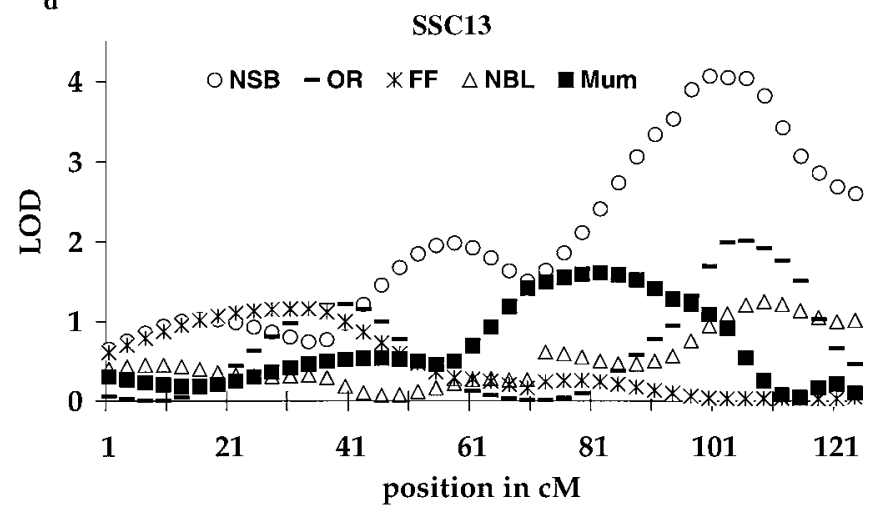

Figure 1. Likelihood ratio test statistic (LOD $=\log _{10}$ of odds) for ovulation rate and number of stillborn (NSB), fully formed (FF), and live (NBL) pigs at birth. (a) chromosome 9, (b) chromosome 11, (c) chromosome 5, (d) chromosome 13.

\section{Results}

\section{Markers}

All markers, their relative positions, and informativeness are listed in Table 2. Informativeness of a marker is the proportion of $\mathrm{F}_{1}$ meioses for which the allelic line of origin could be determined. The program by Haley et al. (1994) uses all available marker information within a linkage group to calculate coefficients of additive and dominance effects. Therefore, the marker informativeness values presented in Table 2 represent informativeness only of that individual marker, and not informativeness at that location.

\section{Phenotypic Means and Standard Deviations}

Phenotypic means, standard deviations, and ranges are reported in Table 3 . The $F_{1}$ generation is expected to have less genetic variance than the $\mathrm{F}_{2}$ generation. However, phenotypic standard deviations for the $\mathrm{F}_{1}$ and $\mathrm{F}_{2}$ generations were similar.

\section{Putative QTL}

All putative QTL, their most probable positions, informativeness and LOD scores at those positions, and estimates of additive effects of the control-line alleles are reported in Table 4. Corresponding plots of LOD ratios are shown in Figures 1, 2, and 3.

Evidence was found for a QTL affecting ovulation rate near marker SW21 on SSC9 $(P<0.05$; Figure 1a; Table 4). The dominance effect was estimated to be 1.16 ova, which was different from zero $(P<0.05)$. The LOD ratio for number of mummified pigs for a QTL in this same region on SSC9 also approached significance (Figure 1a).

Putative QTL for number of fully formed $(P<0.05$, Figure $1 \mathrm{~b}$, Table 4$)$ and live pigs $(P<0.10$, Figure $1 \mathrm{~b}$, Table 4) at birth were identified on SSC11. Additive effects of the allele inherited from the Control line were estimated to be $-0.86 \pm 0.27(P<0.05)$ and $-0.83 \pm 0.3$ $(P<0.05)$ pigs, respectively. Maximum LOD ratios for ovulation rate and number of stillborn pigs also occurred in this same region of SSC11, supporting evidence for a QTL on SSC11 affecting litter size.

For number of stillborn pigs, putative QTL were identified on SSC5 $(P<0.05$, Figure 1c, Table 4$)$ and SSC13 $(P<0.05$, Figure $1 \mathrm{~d}$, Table 4$)$. The estimated dominance effect for a QTL at position $131 \mathrm{cM}$ on SSC5 was 1.13 $\pm 0.36(P<0.05)$. There was little supporting evidence from correlated traits for this QTL (Figure 1c). However, the LOD ratio for number of mummified pigs did 
peak in this same region of SSC5. At position $101 \mathrm{cM}$ on SSC13, the estimated additive and dominance effects for number of stillborn pigs were $-0.43 \pm 0.13(P<$ $0.05)$ and $-0.5 \pm 0.23(P<0.05)$. Figure $1 \mathrm{~d}$ also shows nonsignificant peaks for ovulation rate and number of live and mummified pigs at birth in this same region of SSC13.

Several putative QTL were identified for number of nipples and age at puberty. Means of Lines I and $\mathrm{C}$ did not differ for age at puberty or number of nipples. Evidence exists for QTL associated with number of nipples on SSC1 $(P<0.10$, Figure 2a), SSC6 $(P<0.10$, Figure 2b), SSC7 $(P<0.10$, Figure 2c), SSC8 $(P<0.05$, Figure 2d), and SSC11 $(P<0.05$, Figure 2e). Putative QTL associated with age at puberty were identified on SSC7 at positions $1 \mathrm{cM}(P<0.05$, Figure $3 \mathrm{a})$ and $58 \mathrm{cM}$ $(P<0.10$, Figure 3a). On SSC8 there were three peaks associated with age at puberty (Figure $3 \mathrm{~b}$ ) at positions
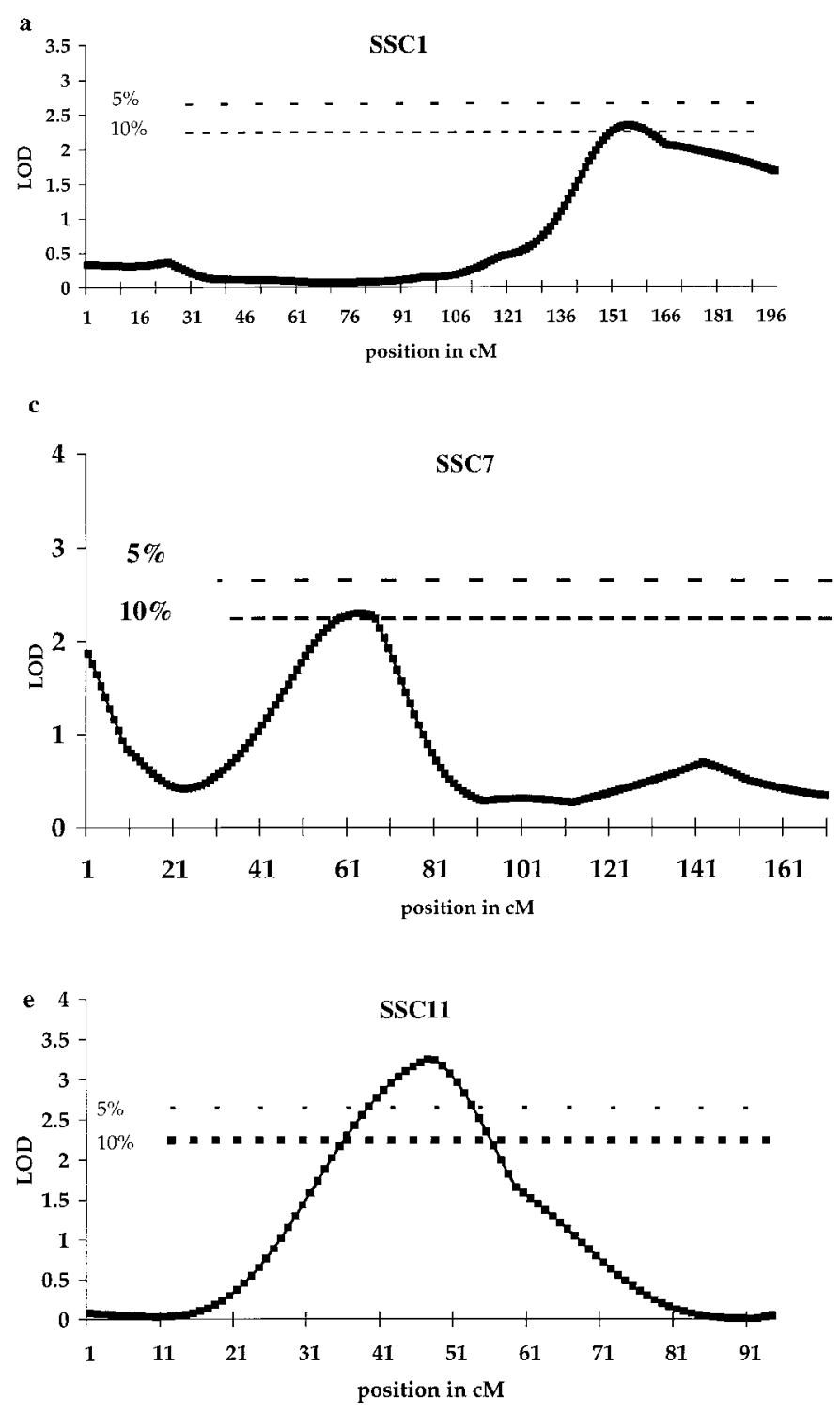

$101(P<0.05), 136(P<0.05)$, and $172(P<0.05)$. At position $9 \mathrm{cM}$ on SSC12, there was evidence $(P<0.10$, Figure 3c) of a QTL affecting age at puberty.

\section{Discussion}

Rathje et al. (1997) reported preliminary results from this project. They found evidence for a QTL affecting ovulation rate on SSC4, SSC8, SSC13, and SSC15. Those QTL were not confirmed in this study. Rathje et al. (1997) used fewer markers and data from Replicate 1 females only. Differences in results of the current analysis and those of Rathje et al. (1997) may be due to sampling variance and different marker data. This highlights the need for powerful QTL analysis, in regard to numbers of meioses and markers, before potential application of results.

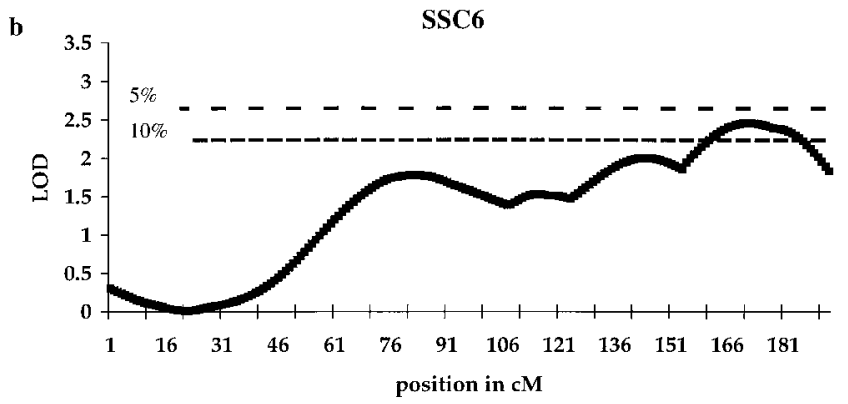

d

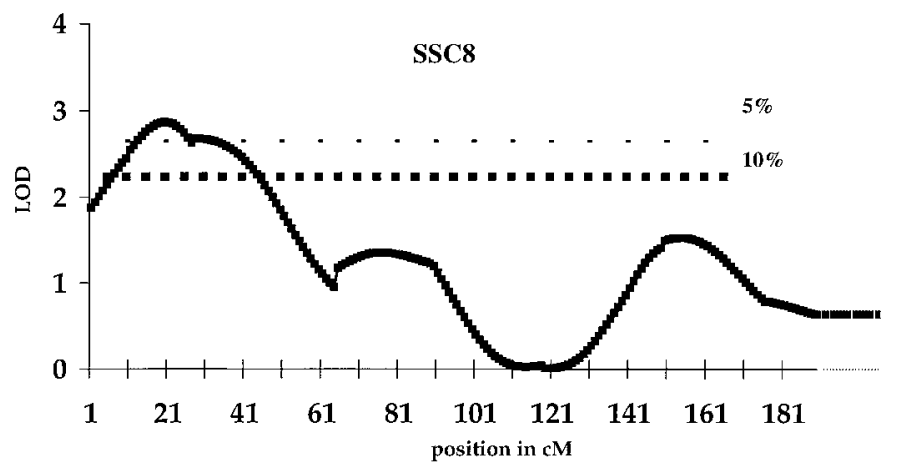

Figure 2. Likelihood ratio test statistic (LOD $=\log _{10}$ of odds) for number of nipples. (a) chromosome 1 , (b) chromosome 6, (c) chromosome 7, (d) chromosome 8, (e) chromosome 11. 
a

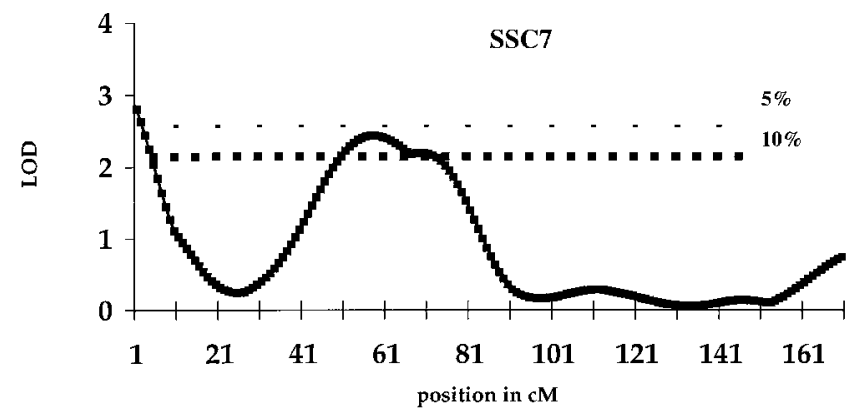

b

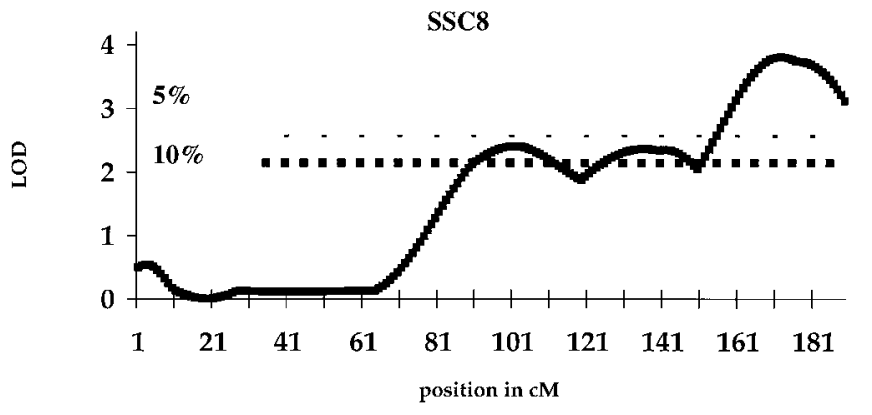

c

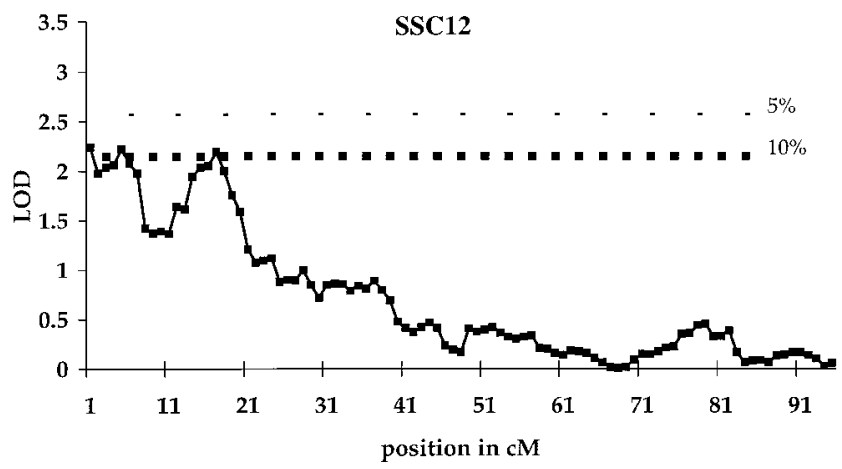

Figure 3. Likelihood ratio test statistic (LOD $=\log _{10}$ of odds) for age at puberty. (a) chromosome 7, (b) chromosome $8,(\mathrm{c})$ chromosome 12.

Estimates of QTL for reproduction in pigs reported elsewhere and those from the present study are summarized in Table 5. The purpose of Table 5 is to compare results from several studies on a common statistical basis and map. Most probable position of each QTL was adjusted to the map published by Rohrer et al. (1996). In addition, test statistics were adjusted to an $F$-statistic for comparison. Expected number of false positives per genome scan was calculated using the methods of Lander and Kruglyak (1995).

In this study, the strongest evidence for a QTL associated with litter size was on SSC13 affecting number of stillborn pigs with most probable position at $101 \mathrm{cM}$. Both the additive effect of $-0.43 \pm 0.13$ pigs and dominance effect of $-0.5 \pm 0.23$ pigs were significant. LOD scores for other litter-size traits did not reach significance on SSC13. However, LOD scores for both ovulation rate and number of pigs born live were maximized in this same region of SSC13. For this putative QTL the additive effect is in the direction expected, and animals inheriting a Line $\mathrm{C}$ allele had fewer stillborn pigs than those inheriting a Line I allele. Knott et al. (1998) reported evidence of a QTL on SSC13 at position $61 \mathrm{cM}$ affecting birth weight. Because the most probable positions of these putative QTL are $40 \mathrm{cM}$ apart, it is unlikely that they are the same QTL.

Wilkie et al. (1999) and Paszek et al. (1999) reported QTL on SSC4 at positions $4 \mathrm{cM}$ and $8 \mathrm{cM}$ affecting number of stillborn pigs and birth weight, respectively. Johnson et al. (1999) reported a decrease in average pig birth weight in Line I relative to Line C. In addition, stillborn pigs weighed significantly less than live pigs in both Lines I and C. Johnson et al. (1999) suggested that selection for increases in litter size and pig birth weight may decrease number of stillborn pigs. Evidence of linked QTL affecting number of stillborn pigs and pig birth weight supports that conclusion.

A putative QTL affecting ovulation rate was found near SW21 on SSC9. Initial estimates of effects of this QTL were an additive effect of $-0.25 \pm 0.23$ and a dominance effect of $1.16 \pm 0.4$ (Table 4). The first marker evaluated on SSC9 was SW21. The LOD score for ovulation rate seems to be increasing at that point (Figure 1a). Thus, the most probable location for a QTL affecting ovulation rate on SSC9 is between markers CCKBR and SW21. Adding more markers may help to better locate the position of this QTL. Rohrer et al. (1999) also reported evidence of a QTL on SSC9 affecting ovulation rate. The most probable locations of the two QTL differed by $56 \mathrm{cM}$; therefore, it is unlikely that these are the same QTL.

Evidence existed for a QTL affecting number of fully formed and live pigs at birth on SSC11. LOD scores for ovulation rate and number of stillborn pigs are maximized in the same region of SSC11. However, informativeness of markers in this region was low. Thus, location of this putative QTL is not well defined. Estimates of the additive effects of these QTL are $-0.85 \pm 0.27$ fully formed pigs and $-0.83 \pm 0.3$ pigs born alive (Table 4 ). These effects are in the direction that would be expected with the allele from Line $\mathrm{C}$ decreasing numbers of fully formed and live pigs at birth. Because these effects are approximately equal, selection for the favorable QTL allele is expected to be equally effective at increasing number of fully formed and live pigs at birth. This evidence seems to be the first for a QTL affecting litter size on SSC11.

Putative QTL associated with ovulation rate have been reported on SSC15 at position $79 \mathrm{cM}$ (Rohrer et al., 1999, Table 5) and at position $100 \mathrm{cM}$ (Wilkie et al., 1999). These QTL are in close proximity to the QTL for ovulation rate reported by Rathje et al. (1997). In the present study the LOD score for ovulation rate on SSC15 was maximized at position $88 \mathrm{cM}(\mathrm{LOD}=1.7)$. These results from three independent studies support evidence for a QTL in this region. Wilkie et al. (1999) found evidence for a QTL at position $42 \mathrm{cM}$ on SSC5 
Table 5. Location, significance, and estimates of additive (a) and dominance (d) effects of reported putative QTL affecting reproduction in the pig

\begin{tabular}{|c|c|c|c|c|c|c|c|c|c|c|}
\hline Trait & $\mathrm{Chr}^{\mathrm{a}}$ & $\mathrm{cM}^{\mathrm{b}}$ & $F$-ratio ${ }^{c}$ & $\mathrm{df}_{\mathrm{n}}^{\mathrm{df}}$ & $\mathrm{df}_{\mathrm{d}}{ }^{\text {ef }}$ & $P$-value ${ }^{g}$ & Genome $^{\mathrm{h}}$ & a & $d$ & Reference \\
\hline Birth weight, $\mathrm{g}$ & 1 & 19 & 6.4 & 2 & 168 & $2.1 \times 10^{-3}$ & 2.05 & $-59.5 \pm 22.1$ & $74.1 \pm 32.8$ & Knott et al., 1998 \\
\hline Age at puberty, $d$ & 1 & 105 & 6.67 & 2 & 344 & $2.2 \times 10^{-4}$ & 0.44 & 9.35 & -5.49 & Rohrer et al., 1999 \\
\hline Number of nipples & 1 & 115 (155) & 5.45 & 2 & 340 & $4.7 \times 10^{-3}$ & 3.91 & $0.17 \pm 0.15$ & $0.7 \pm 0.29$ & Present study \\
\hline Gestation length, $d$ & 1 & $94(166)$ & 5.22 & 2 & 103 & $6.9 \times 10^{-3}$ & 5.56 & $1.18 \pm 0.55$ & $0.62 \pm 1.09$ & Wilkie et al., 1999 \\
\hline Number of corpora lutea & 3 & 36 & 12.72 & 1 & 288 & $4.0 \times 10^{-4}$ & 0.55 & -2.2 & 0 & Rohrer et al., 1999 \\
\hline Number of stillborn pigs & 4 & $4(1)$ & 9.97 & 2 & 98 & $1.0 \times 10^{-4}$ & 0.17 & $-0.31 \pm 0.11$ & $-0.57 \pm 0.18$ & Wilkie et al., 1999 \\
\hline Birth weight, g & 4 & $8(33)$ & 8.04 & 2 & 170 & $4.6 \times 10^{-4}$ & 0.56 & $-46 \pm 17$ & $85 \pm 28$ & Paszek et al., 1999 \\
\hline Uterine length, cm & 5 & $42(1)$ & 5.13 & 2 & 104 & $7.5 \times 10^{-3}$ & 5.92 & $87.2 \pm 27.4$ & $-31.5 \pm 54.1$ & Wilkie et al., 1999 \\
\hline Number of stillborn pigs & 5 & $85(131)$ & 6.5 & 2 & 279 & $1.7 \times 10^{-3}$ & 1.73 & $-0.87 \pm 0.19$ & $1.13 \pm 0.36$ & Present study \\
\hline Number of fully formed pigs & 6 & $104(102)$ & 5.15 & 2 & 98 & $7.5 \times 10^{-3}$ & 5.91 & $-0.81 \pm 0.49$ & $1.94 \pm 0.65$ & Wilkie et al., 1999 \\
\hline Number of nipples & 6 & $145(171)$ & 5.76 & 2 & 340 & $3.4 \times 10^{-3}$ & 3.06 & $-0.35 \pm 0.12$ & $0.17 \pm 0.23$ & Present study \\
\hline Age at puberty, $d$ & 7 & $4(1)$ & 6.67 & 2 & 212 & $1.5 \times 10^{-3}$ & 1.6 & $-2.4 \pm 2.1$ & $10.5 \pm 3.2$ & Present study \\
\hline Age at puberty, $d$ & 7 & $55(58)$ & 5.75 & 2 & 212 & $3.7 \times 10^{-3}$ & 3.27 & $-3.2 \pm 2.4$ & $-10.8 \pm 4.1$ & Present study \\
\hline Number of nipples & 7 & $59(62)$ & 5.38 & 2 & 340 & $5.0 \times 10^{-3}$ & 4.14 & $-0.2 \pm 0.11$ & $-0.41 \pm 0.17$ & Present study \\
\hline Uterine length, $\mathrm{cm}$ & 7 & $154(148)$ & 5.71 & 2 & 104 & $4.4 \times 10^{-3}$ & 3.88 & $20.5 \pm 33.5$ & $-180.9 \pm 57.6$ & Wilkie et al., 1999 \\
\hline Number of corpora lutea & 7 & $156(150)$ & 6.22 & 2 & 104 & $2.8 \times 10^{-3}$ & 2.67 & $2.57 \pm 0.73$ & $1.33 \pm 1.21$ & Wilkie et al., 1999 \\
\hline Number of corpora lutea & 8 & 5 & 26.71 & 2 & 288 & $4.4 \times 10^{-7}$ & 0 & -2.87 & 0 & Rohrer et al., 1999 \\
\hline Number of nipples & 8 & $19(15)$ & 6.74 & 2 & 340 & $1.3 \times 10^{-3}$ & 1.39 & $-0.29 \pm 0.12$ & $0.36 \pm 0.19$ & Present study \\
\hline Number of corpora lutea & 8 & $50(101)$ & 8.89 & 2 & 104 & $2.7 \times 10^{-4}$ & 0.37 & $-1.20 \pm 0.37$ & $-1.76 \pm 0.63$ & Wilkie et al., 1999 \\
\hline Age at puberty, $d$ & 8 & $70(101)$ & 5.7 & 2 & 212 & $3.9 \times 10^{-3}$ & 3.4 & $7.7 \pm 2.9$ & $7.4 \pm 4.6$ & Present study \\
\hline Uterine capacity & 8 & 71 & 7.87 & 2 & 187 & $5.2 \times 10^{-4}$ & 0.83 & 1.99 & 1.43 & Rohrer et al., 1999 \\
\hline Number of corpora lutea & 8 & 110 & 7.38 & 2 & 75 & $1.2 \times 10^{-3}$ & 1.35 & 3.07 & -5.35 & Rathje et al. 1997 \\
\hline Age at puberty, $d$ & 8 & $110(136)$ & 5.58 & 2 & 212 & $4.4 \times 10^{-3}$ & 3.73 & $7.1 \pm 2.4$ & $-2.6 \pm 4$ & Present study \\
\hline Age at puberty, $d$ & 8 & $120(172)$ & 9.15 & 2 & 212 & $1.5 \times 10^{-4}$ & 0.21 & $7.2 \pm 2.4$ & $-10.6 \pm 4.5$ & Present study \\
\hline Weight of ovary, $\mathrm{g}$ & 8 & 122 & 6.55 & 3 & 270 & $2.7 \times 10^{-4}$ & 0.54 & 1.04 & 0.26 & Rohrer et al., 1999 \\
\hline Number of corpora lutea & 9 & $11(1)$ & 6.19 & 2 & 340 & $2.3 \times 10^{-3}$ & 2.17 & $-0.25 \pm 0.23$ & $1.16 \pm 0.4$ & Present study \\
\hline Number of corpora lutea & 9 & 67 & 5.78 & 3 & 286 & $7.6 \times 10^{-4}$ & 1.32 & -1.98 & 0.10 & Rohrer et al., 1999 \\
\hline Gestation length, d & 9 & 130 (135) & 9.3 & 2 & 103 & $1.9 \times 10^{-4}$ & 0.27 & $1.52 \pm 0.44$ & $-2.34 \pm 0.75$ & Wilkie et al., 1999 \\
\hline Number of corpora lutea & 10 & 89 & 7.62 & 2 & 287 & $6.0 \times 10^{-4}$ & 0.92 & -2.26 & -1.22 & Rohrer et al., 1999 \\
\hline Age at puberty, $d$ & 10 & 125 & 6.92 & 3 & 344 & $1.6 \times 10^{-4}$ & 0.33 & -27.58 & -11.20 & Rohrer et al., 1999 \\
\hline Number of nipples & 11 & $45(46)$ & 7.65 & 2 & 340 & $5.6 \times 10^{-4}$ & 0.65 & $-0.03 \pm 0.11$ & $0.68 \pm 0.19$ & Present study \\
\hline Number of fully formed pigs & 11 & $51(52)$ & 6.6 & 2 & 279 & $1.6 \times 10^{-3}$ & 1.6 & $-0.86 \pm 0.27$ & $-0.04 \pm 0.47$ & Present study \\
\hline Number of pigs born alive & 11 & $67(71)$ & 5.97 & 2 & 279 & $2.9 \times 10^{-3}$ & 2.64 & $-0.83 \pm 0.3$ & $0.66 \pm 0.61$ & Present study \\
\hline Birth weight, g & 12 & 0 & 5.4 & 2 & 168 & $5.3 \times 10^{-3}$ & 4.42 & $-36.6 \pm 37.1$ & $-303.3 \pm 94.6$ & Knott et al., 1998 \\
\hline Age at puberty, $d$ & 12 & $15(9)$ & 5.29 & 2 & 212 & $5.7 \times 10^{-3}$ & 4.67 & $-5.4 \pm 2.3$ & $-0.89 \pm 3.9$ & Present study \\
\hline Birth weight, g & 13 & 61 & 6.5 & 2 & 168 & $1.9 \times 10^{-3}$ & 1.9 & $75.4 \pm 21.1$ & $11.8 \pm 28.5$ & Knott et al., 1998 \\
\hline Number of stillborn pigs & 13 & $101(101)$ & 9.7 & 2 & 279 & $8.5 \times 10^{-5}$ & 0.12 & $-0.43 \pm 0.13$ & $-0.5 \pm 0.23$ & Present study \\
\hline Number of corpora lutea & 15 & 79 & 5.73 & 3 & 286 & $7.4 \times 10^{-4}$ & 1.4 & 2.44 & 0.25 & Rohrer et al., 1999 \\
\hline Gestation length, d & 15 & $89(96)$ & 6.79 & 2 & 103 & $1.7 \times 10^{-3}$ & 1.76 & $1.86 \pm 0.54$ & $1.01 \pm 1.06$ & Wilkie et al., 1999 \\
\hline Number of corpora lutea & 15 & $100(107)$ & 6.2 & 2 & 104 & $2.9 \times 10^{-3}$ & 2.71 & $-0.81 \pm 0.59$ & $3.84 \pm 1.13$ & Wilkie et al., 1999 \\
\hline
\end{tabular}

${ }^{\mathrm{a}}$ Chromosome on which the putative QTL was reported.

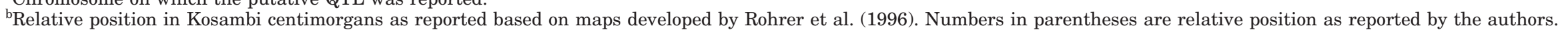

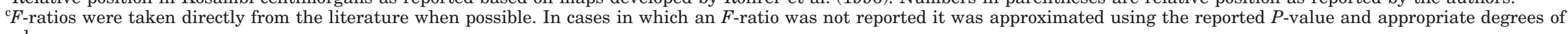
freedom.

${ }^{\mathrm{d}}$ If degrees of freedom were not reported in the article they were approximated based on the reported model and number of animals.

eNumerator degrees of freedom.

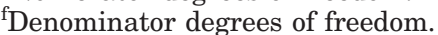

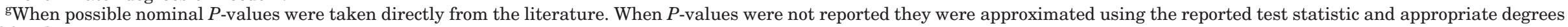
of freedom.

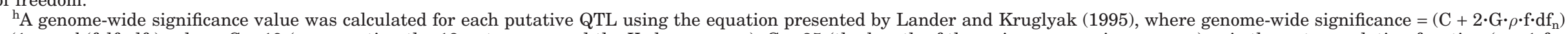

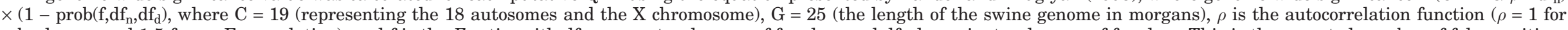

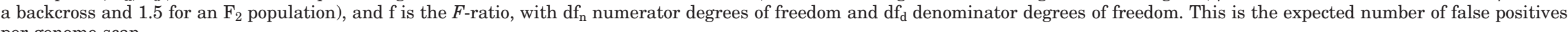
per genome scan. 
for uterine length. The present study provides evidence for a QTL for number of stillborn pigs at position 85 cM on SSC5. Short et al. (1997) reported a favorable association between the $\mathrm{B}$ allele at the estrogen receptor (ESR, SSC1 position $19 \mathrm{cM}$ ) locus and total number of pigs born and born live in a Large White-based commercial line. Knott et al. (1998) reported a QTL near the location of the ESR locus associated with pig birth weight. Rohrer et al. (1999) reported no association between the ESR locus and reproductive traits in a reference population developed from Chinese Meishan and the white line composite of Landrace, Large White, Yorkshire, and Chester White at MARC. The Nebraska reference population was screened for the ESR marker (Short et al., 1997), which was found to be uninformative. The ESR locus also did not explain the selection response in lines derived from the Nebraska index line that were selected for ovulation rate and litter size (Linville et al., 1999), and no evidence for QTL influencing litter size was found in the region of SSC1 harboring the ESR locus.

Several QTL affecting nipple number were identified. Nipple number is easily measured in both males and females and is not a likely candidate for MAS. However, QTL associated with nipple number may provide an opportunity for greater understanding of biological function.

Quantitative trait loci affecting age at puberty on SSC7, SSC8, and SSC12 were identified. In addition, Rohrer et al. (1999) has identified QTL affecting age at puberty on SSC1 and SSC10. Additive effects of these QTL ranged from -5 to $27 \mathrm{~d}$. Potential may exist to change age at puberty using marker-assisted selection. Age at puberty is an economically important trait that is laborious to measure.

The present study is the first to complete a wholegenome scan using an $\mathrm{F}_{2}$ cross between selection lines of pigs originating from a common base population. Casas-Carrillo et al. (1997) searched for growth QTL in half-sib families from $\mathrm{F}_{1}$ sires arising as a result of the cross of lines divergently selected for growth rate. The use of crosses of selection lines for QTL discovery has inherent limitations and benefits. In contrast to other pig reproduction QTL scans (Rohrer et al., 1999; Wilkie et al., 1999), both of which used Meishan-White crosses, the power of the present experiment was limited by lower marker informativeness and less phenotypic divergence for some traits. Conversely, findings from crosses between lines with commercially viable phenotypes will have more immediate application to the industry. Favorable alleles originating from Meishan or other Chinese breeds of pigs must be slowly introgressed into commercially relevant lines or breeds.

Finally, use of selection line crosses enables examination of the nature of selection response at the QTL level. Our results indicate that few, if any, major genes for reproductive traits were segregating in the Large White $\times$ Landrace composite base population. Possible exceptions are the QTL found for litter size on SSC11. How- ever, informativity at that point was low, and thus the QTL effect is not precisely estimated. It is likely that selection for ovulation rate, embryonic survival, and litter size in this population has acted on many loci, each with modest to small effect. Much greater experimental power is necessary to genetically dissect such polygenic traits.

\section{Implications}

Putative QTL affecting reproduction in pigs were identified. Informativeness at the most probable position of some of these putative QTL was less than $50 \%$. In those cases, fewer than 400 meioses observed in $\mathrm{F}_{2}$ animals were informative at the marker locus. Therefore, additional informative markers should be genotyped in this population to obtain more information and possibly identify false positives. Confirmation of these putative QTL in other populations is also needed. At present, insufficient information exists to encourage marker-assisted selection. However, putative QTL with significant effects associated with litter size, number of corpora lutea, number of nipples, and age at puberty have been identified.

\section{Literature Cited}

Bennett, G. L., and K. A. Leymaster. 1989. Integration of ovulation rate, potential embryonic viability and uterine capacity into a model of litter size in swine. J. Anim. Sci. 67:1230-1241.

Casas-Carrillo, E., A. Prill-Adams, S. G. Price, A. C. Clutter, and B. W. Kirkpatrick. 1997. Mapping genomic regions associated with growth rate in pigs. J. Anim. Sci. 75:2047-2053.

Churchill, G. A., and R. W. Doerge. 1994. Empirical threshold values for quantitative trait mapping. Genetics 138:963-971.

Edwards, M. D., and N. J. Page. 1994. Evaluation of marker-assisted selection through computer simulation. Theor. Appl. Genet. 88:376-382.

Green, P., K. Falls, and S. Crooks. 1990. Documentation for CRIMAP, version 2.4. Washington Univ. School of Medicine, St. Louis, MO.

Haley, C. S., S. A. Knott, and J.-M. Elsen. 1994. Mapping quantitative trait loci in crosses between outbred lines using least squares. Genetics 136:1195-1207.

Johnson, R. K., M. K. Nielsen, and D. S. Casey. 1999. Responses in ovulation rate, embryonal survival, and litter traits in swine to 14 generations of selection to increase litter size. J. Anim. Sci. 77:541-557.

Johnson, R. K., D. R. Zimmerman, and R. J. Kittok. 1984. Selection for components of reproduction in swine. Livest. Prod. Sci. 11:541-558.

Keele, J. W., J. E. Wray, D. W. Behrens, G. A. Rohrer, S. L. F. Sunden, S. M. Kappes, M. D. Bishop, R. T. Stone, L. J. Alexander, and C. W. Beattie. 1994. A conceptual database model for genomic research. J. Comput. Biol. 1:65-76.

Knott, S. A., L. Marklund, C. S. Haley, K. Andersson, W. Davies, H. Ellegren, M. Fredholm, I. Hansson, B. Hoyheim, K. Lundström, M. Moller, and L. Andersson. 1998. Multiple marker mapping of quantitative trait loci in a cross between outbred wild boar and large white pigs. Genetics 149:1069-1080.

Lamberson, W. R., R. K. Johnson, D. R. Zimmerman, and T. E. Long. 1991. Direct responses to selection for increased litter size, decreased age at puberty, or random selection following selection for ovulation rate in swine. J. Anim. Sci. 69:3129-3143. 
Lande, R., and R. Thompson. 1990. Efficiency of marker-assisted selection in the improvement of quantitative traits. Genetics 124:743-756.

Lander, E., and L. Kruglyak. 1995. Genetic dissection of complex traits: guidelines for interpreting and reporting linkage results. Nat. Genet. 11:241-358.

Linville, R. C., R. K. Johnson, and D. Pomp. 1999. Candidate gene analysis for loci affecting reproductive traits in swine selected for litter size and ovulation rate. J. Anim. Sci. 77(Suppl. 1):131 (Abstr.).

Ollivier, L. 1982. Selection for prolificacy in the pig. Pig News Info. 3:383-388.

Paszek, A. A., P. J. Wilkie, G. H. Flickinger, G. A. Rohrer, L. J. Alexander, C. W. Beattie, and L. B. Schook. 1999. Interval mapping of growth in divergent swine cross. Mamm. Genome 10:117-122.

Rathje, T. A., G. A. Rohrer, and R. K. Johnson. 1997. Evidence of quantitative trait loci affecting ovulation rate in pigs. J. Anim. Sci. 75:1486-1494.

Rohrer, G. A., L. J. Alexander, Z. Hu, T. P. L. Smith, J. W. Keele, and C. W. Beattie. 1996. A comprehensive map of the porcine genome. Genome Res. 6:371-391.
Rohrer, G. A., J. J. Ford, T. H. Wise, J. L. Vallet, and R. K. Christenson. 1999. Identification of quantitative trait loci affecting female reproductive traits in a multigeneration Meishan-White composite swine population. J. Anim. Sci. 77:1385-1391.

Short, T. H., M. F. Rothschild, O. I. Southwood, D. G. McLaren, A. de Vries, H. van der Steen, G. R. Eckardt, C. K. Tuggle, J. Helm, D. A. Vaske, A. J. Mileham, and G. S. Plastow. 1997. Effect of the estrogen receptor locus on reproduction and production traits in four commercial pig lines. J. Anim. Sci. 75:3138-3142.

USDA. 1996. United States Department of Agriculture home page. Available at: http://www.marc.usda.gov/genome/swine/. Accessed 1996 through 1998.

Wilkie, P. J., A. A. Paszek, C. W. Beattie, L. J. Alexander, M. B. Wheeler, and L. B. Schook. 1999. A genomic scan of porcine reproductive traits reveals possible quantitative trait loci (QTLs) for number of corpora lutea. Mamm. Genome 10:573-578.

Zhang, W., and C. Smith. 1992. Computer simulation of markerassisted selection utilizing linkage disequilibrium. Theor. Appl. Genet. 83:813-820.

Zhang, W., and C. Smith. 1993. Simulation of marker-assisted selection utilizing linkage disequilibrium: the effects of several additional factors. Theor. Appl. Genet. 86:492-496. 